\title{
Altitude Variation in Volatile Composition of Blueberry Leaf Analyzed by SPME GC-MS
}

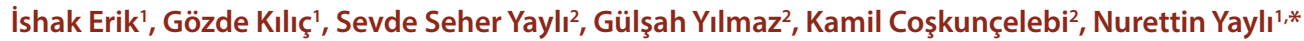 \\ 'Department of Pharmacognosy, Faculty of Pharmacy, Karadeniz Technical University, Trabzon, TURKEY. \\ 2Department of Biology, Faculty of Science, Karadeniz Technical University, Trabzon, TURKEY.
}

\begin{abstract}
Background: The present work was aimed to carry out volatile component analyzes in Vaccinium arctostaphlyos L., V. uliginosum L., V. vitis-idaea L. and $V$. myrtillus $L$ leaf growing at different altitudes of the East Blacksea Region of Turkey. Methods: The leaf of Vaccinium species were harvested from twenty-one different altitudes $(748-3035 \mathrm{~m})$ from six cities (ArtvinArdahan-Rize-Trabzon-Gümüşhane-Giresun) of Turkey. The diversity of volatiles in the leaf was investigated by SPME GC-FID/MS. Results: The major constituents of the Vaccinium leaf showed variation with changes in altitudes. The identified volatile components of $V$. arctostaphlyos and $V$. uliginosum were represented mainly by aldehydes in all altitudes, whereas monoterpenes were found the major constituent of $V$. vitis-idaea at Posof-Ardahan $(2376 \mathrm{~m})$ and Artvin $(2553 \mathrm{~m})$ samples. In all altitudes, capronaldehyde (7.23-28.96\%) and 2(E)-hexenal (8.90-53.59\%) in the leaf of $V$. arctostaphlyos; capronaldehyde (17.04-37.09\%) and limonene (16.50$47.51 \%)$ in the leaf of $V$. vitis-idaea and capronaldehyde $(4.55-39.90 \%)$, 2(E)-hexenal $(25.08-80.99 \%)$ and hexadecane $(2.97-11.32 \%)$ in the leaf of V. uliginosum; and capronaldehyde (14.66-37.26\%) and 2(E)-hexenal
\end{abstract}

(18.18-37.59\%) at the altitudes of $1912 \mathrm{~m}, 2533 \mathrm{~m}$ and $2565 \mathrm{~m}$ in the leaf of $V$. myrtillus were the major constituents with the different percentages, respectively. 2-Bornanone (32.86\%) at the altitude of $2613 \mathrm{~m}$ and 3-penten2-one $(93.60 \%)$ at the altitude of $2811 \mathrm{~m}$ in the leaf of $V$. myrtillus were found to be the major compounds. Conclusion: Comparisons of the volatile components of $V$. arctostaphlyos, $V$. uliginosum, $V$. vitis-idaea and $V$. myrtillus in different sites showed significant differences among populations at different altitudes.

Key words: Vaccinium arctostaphlyos, V. uliginosum, V. vitis-idaea, V. myrtillus, SPME GC-FID/MS.

\section{Correspondence}

\section{Prof. Nurettin Yaylı}

Department of Pharmacognosy, Faculty of Pharmacy, Karadeniz Technical University, Trabzon, TURKEY.

Phone no: +90-05333153187

Email: yayli@ktu.edu.tr

DOI: 10.5330/ijpi.2020.4.90

\section{INTRODUCTION}

The genus Vaccinium L. (Ericaceae) is represented approximately with 450 species of shrubs or small trees worldwide. ${ }^{1}$ Four of the species (V. arctostaphlyos $(V a), V$. uliginosum $(V u), V$. vitis-idaea $(V v i)$ and $V$. myrtillus $(V m))$ occur in Turkey and these are mostly distributed in North-East and North-West Anatolia. ${ }^{2}$ Vaccinium is a medicinal plant that leaf consist on deciduous or evergreen and berries are vary from blue, purple, black or red. Berries can be eaten fresh; leaf can be dried and steeped. Also Vaccinium leaf, flower, berries and rhizomes are more usually processed. ${ }^{3}$ The genus is rich sources of dietary anthocyanins and antioxidants. Leaf and berries are traditionally used in for the treatment of diabetes ${ }^{4,5}$ and also including antimicrobial, antiinflammatory and antimutagenic properties. ${ }^{6,7}$ Vaccinium species are an industrial medicinal plant with various pharmaceutical and nutritional applications. Major constituents of the essential oil of Vaccinium species were mentioned to be as; $\alpha$-terpineol (14.99\%) and linalool (13.7\%) for $V a{ }^{8}$ nerolidol (20.01\%), (Z,Z,Z)-1,5,9,9-tetramethyl-1,4,7-cycloundecatriene (17.99\%) and caryophyllene (9.59\%) for Vaccinium bracteatum Thumb. ${ }^{9}$ $\alpha$-terpineol (4.7\%) and linalool (17.0\%) for $V v i ;^{10} \alpha$-pinene $(15.5 \%)$, linalool (11.7\%), sandaracopimaradiene (5.9\%) and safranal (8.8\%) for V. arctostaphylos; ${ }^{11}$ diisobutyl phthalate for $V v i(17.96 \%) ;{ }^{12}$ decahydro dimethylnaphthalene (47.04\%), linalool (3.19\%), 3,7-dimethyl-1,5,7octatrien-3-ol (1.40\%) and benzene acetaldehyde (1.03\%) for Vaccinium dunalianum var. dunalianum (C. B. Clarke) Ridley; ${ }^{13} \alpha$-pinene for Vaccinium angustifolium Aiton, (23\%) and Vaccinium arboreum Marsh., (63\%), methyl benzoate for Vaccinium varingiaefolium Miq., (18\%) and ethyl benzene for Vaccinium poasanum Donn. Sm. (21\%); ${ }^{14}$ and butyl butanoate, cis-3-hexen-1-ol, $\alpha$-terpineol, geraniol and trans-2-hexenal for Vaccinium corymbosum L. ${ }^{15}$ HS SPME GC-MS analysis for fruit juice of $\mathrm{Vm}$ were mentioned. ${ }^{16}$ The complexity of blueberry $(\mathrm{Vm})$ aroma was explored by SPME GC-MS and VOCs were reported as aldehydes, alcohols, terpenoids and esters. ${ }^{17}$ Volatile compounds, the antifungal activity and the phytotoxic activity of essential oil of $V m$ were also reported. ${ }^{18,19}$ In the literature, polar metabolites of leaf of $V m$ and $V v i$ were also studied by HPLC-DAD, HPLC-MS and GC-FID,${ }^{20}$ and the extracts of entire fruits and leaf of $\mathrm{Vm}$ collected in Finland and Poland were quantitated by GC-FID/MS and the main bilberry constituents were given as $\alpha$-and $\beta$-amyrin, $\alpha$ - and $\beta$-amyrenone, campesterol, cholesterol and citrostadienol. ${ }^{21}$ However, to the best of our knowledge of literature survey, no data about altitude variation in volatile composition of $\mathrm{Va}$, $V u, V v i$ and $V m$ leaf analyzed by SPME GC-MS have been reported up to date. The present study aim to test whether there is any altitude effect on volatile compounds of $\mathrm{Va}, \mathrm{Vu}, \mathrm{Vvi}$ and $\mathrm{Vm}$ leaf growing spontaneously in different altitudes in the East Blacksea region of Turkey.

\section{MATERIALS AND METHODS}

\section{Plant materials}

$V a, V u, V v i$ and $V m$ leaf (25 g, wet) were harvested from different altitudes in the East Blacksea Region (Artvin-Ardahan-Rize-TrabzonGümüşhane-Giresun) of Turkey (Table 1) and were identified. ${ }^{2,3}$ 
Vouchers were deposited in the Herbarium of Biology (KTUB) at Karadeniz Technical University, Turkey (Table 1).

\section{Solid Phase Micro Extraction (SPME)}

The blended leaf $(2 \mathrm{~g})$ were place to a sealed SPME vial $(10 \mathrm{~mL})$ with a silicone-rubber septum cap then submitted to solid-phase micro extraction device (Supelco, USA). A DVB/Carboxen/PDMS coating fiber was used to obtain volatile components. The SPME fibers were conditioned for $5 \mathrm{~min}$ at $250^{\circ} \mathrm{C}$ in the GC injector. Extraction were achieved with magnetic stirring at $80^{\circ} \mathrm{C}$ using an incubation time of $5 \mathrm{~min}$ and an extraction time of $10 \mathrm{~min}$. Fiber with extract of volatile compounds were subsequently injected into the GC injector. Each sample was analyzed and reported. Conditioning time for subsequent assays was set at $4 \mathrm{~min}$ of desorption after each extraction. The temperature, incubation and extraction times were set according to the reported experiment. ${ }^{22-24}$

\section{Gas chromatography-Mass spectrometry (GC-FID/MS)}

The gas chromatography-flame ionization detector (GC-FID) analysis was carried out on a Shimadzu QP2010 plus gas chromatography equipped with a flame ionization detector (FID) using a Rtx-5MS capillary column ( $30 \mathrm{~m} \times 0.25 \mathrm{~mm}$, film thickness, $0.25 \mu \mathrm{m})$. Shimadzu QP2010 Plus gas chromatograph was coupled to a Shimadzu QP2010 Ultra mass selective detector. The injection was performed in split mode
(1:30) at $230^{\circ} \mathrm{C}$. The column held initially at $60^{\circ} \mathrm{C}$ for $2 \mathrm{~min}$ and then increased to $240^{\circ} \mathrm{C}$ with a $3^{\circ} \mathrm{C} / \mathrm{min}$ heating ramp. The oven program was as follows: the initial temperature was $60^{\circ} \mathrm{C}$ for $2 \mathrm{~min}$, which was increased to $240^{\circ} \mathrm{C}$ at $3 \mathrm{~min}$, the final temperature of $250^{\circ} \mathrm{C}$ was held for 4 min. Helium (99.999 \%) was used as carrier gas with a constant flow-rate of $1 \mathrm{~mL} / \mathrm{min}$. Detection was implemented in electronic impact mode (EI); ionization voltage was fixed at $70 \mathrm{eV}$, scan mode $(40-450 \mathrm{~m} / \mathrm{z})$ was used for mass acquisition. ${ }^{22-25}$ Each sample was analyzed and mean reported.

\section{Identification of Volatile Constituents}

Retention indices of the volatile components of leaf belong to four Vaccinium species were determined by Kovats method using $n$-alkanes $\left(\mathrm{C}_{6}-\mathrm{C}_{32}\right)$ as standards. ${ }^{26}$ Volatile compounds were identified by comparing mass spectra and Kovats' Retention Indices with those in literature ${ }^{22-31}$ and by computer searching followed by matching the mass spectra data with those held in computer library (NIST, Wiley7NL, FFNSC1.2 and W9N11)

\section{RESULTS}

The volatile compounds of leaf belong to four Vaccinium species collected from different altitudes in the East Blacksea Region of Turkey were analyzed by SPME GC-FID/MS. A total of 16, 23, 13, 21, 16,

Table 1: Examined species, voucher numbers, collection data and localities of the Vaccinium species in Turkey

\begin{tabular}{|c|c|c|c|c|}
\hline Sample & Harvested localities & $\begin{array}{l}\text { Altitude } \\
\text { (m) }\end{array}$ & $\begin{array}{c}\text { Harvested } \\
\text { date }\end{array}$ & $\begin{array}{l}\text { Collection } \\
\text { number }\end{array}$ \\
\hline \multicolumn{5}{|c|}{ Vaccinium arctostaphylos $(\mathrm{Va})$} \\
\hline$V a 1$ & A8 Rize: Ardeşen, Işıklı village, path route, forestry region & 748 & 19 viii 2017 & C\&Y-46 \\
\hline$V a 2$ & A8 Rize: Ardeşen, Siprona plateau, forestry regions & 1032 & 19 viii 2017 & C\&Y-47 \\
\hline Va3 & A7 Trabzon: Araklı, Köyiçi village, forestry regions & 1443 & 06 vii 2017 & C\&Y-15 \\
\hline $\mathrm{Va} 4$ & A7 Trabzon: Düzköy, Çayırbağı, Kale river, forestry regions & 1516 & 06 vii 2017 & C\&Y-21 \\
\hline Va5 & A7 Giresun: Doğankent, Harmancık plateau, forestry regions & 1666 & 02 vii 2017 & $\mathrm{C} \& \mathrm{Y}-14$ \\
\hline Va6 & A7 Gümüşhane: Kürtün above plateau, forestry regions & 1845 & 01 vii 2017 & $\mathrm{C} \& \mathrm{Y}-1$ \\
\hline $\mathrm{Va} 7$ & A8 Artvin: Şavşat, Pınarlı plateau, forestry regions & 2105 & 07 ix 2018 & C\&Y-117 \\
\hline $\mathrm{Va} 8$ & A8 Artvin: Murgul, Tiryol mountain, forestry regions & 2234 & 10 vii 2018 & C\&Y-91 \\
\hline \multicolumn{5}{|c|}{ Vaccinium uliginosum $(\mathrm{Vu})$} \\
\hline$V u 1$ & A8 Artvin: Şavşat, Karagöl National Park, alpine meadows & 2530 & 02 vii 2018 & C\&Y-95 \\
\hline$V u 2$ & A8 Rize: İkizdere, Anzer plateau, alpine meadows & 2537 & 02 ix 2018 & C\&Y-108 \\
\hline$V u 3$ & A9 Ardahan: Hanak, Alabalık plateau, alpine meadows & 2588 & 08 vii 2018 & C\&Y-101 \\
\hline$V u 4$ & A7 Trabzon: Çaykara, Multat plateau, alpine meadows & 2811 & 20 vi 2018 & C\&Y-93 \\
\hline$V u 5$ & A8 Rize: İkizdere, Ovit Lake, alpine meadows & 3035 & 20 viii 2017 & C\&Y-61 \\
\hline \multicolumn{5}{|c|}{ Vaccinium vitis-idaea (Vvi) } \\
\hline Vvil & A9 Ardahan: Hanak, Alabalık plateau, alpine meadows & 2362 & 03 vii 2018 & C\&Y-103 \\
\hline Vvi2 & A9 Ardahan: Posof, Sesödile Hill, alpine meadows & 2376 & $07 \times 2017$ & C\&Y-75 \\
\hline Vvi3 & A8 Artvin: Şavşat Karagöl National Park, alpine meadows & 2533 & $06 \times 2017$ & C\&Y-69 \\
\hline \multicolumn{5}{|c|}{ Vaccinium myrtillus (Vm) } \\
\hline$V m 1$ & A7 Gümüşhane: Kürtün, Süme Village, alpine meadows & 1917 & 01 vii 2017 & C\&Y-5 \\
\hline$V m 2$ & A8 Artvin: Şavşat, Kirazlı Village, alpine meadows & 2533 & 02 vii 2018 & C\&Y-98 \\
\hline$V m 3$ & A8 Rize: Ardeşen, Fındıklı Plateau, alpine meadows & 2565 & 19 viii 2017 & C\&Y-52 \\
\hline$V m 4$ & A9 Ardahan: Hanak, Alabalık Plateau, alpine meadows & 2613 & $08 \times 2018$ & C\&Y-102 \\
\hline$V m 5$ & A7 Trabzon: Çaykara, Multat Plateau, alpine meadows & 2811 & 20 vi 2018 & C\&Y-94 \\
\hline
\end{tabular}

${ }^{a}$ C\&Y: Coşkunçelebi and Yllmaz. 
12,14 and 17 volatile compounds were identified from the leaf of $\mathrm{Va}$, which were collected from different altitudes in Rize-Rize-TrabzonTrabzon-Giresun-Gümüşhane-Artvin-Artvin, respectively. Aldehydes, aliphatic hydrocarbons and aromatics were the largest group of volatiles, accounting for $44.61-77.06 \%, 8.59-22.01 \%$ and $3.42-23.19 \%$ of total volatiles, respectively (Table 2 ). In all altitudes, capronaldehyde (7.2328.96\%), 2(E)-hexenal (8.90-53.59\%) and nonanal (4.24-10.03\%) were generally major compounds in the leaf of $\mathrm{Va}$.

A total of 6 to 8 volatile constituents were characterized from the leaf of $V u$, which were harvested from different altitudes in Artvin-
Rize-Ardahan-Trabzon-Rize, respectively (Table 3). Aldehydes and aliphatic hydrocarbons were the major group of volatiles in the leaf of $V u$, accounting for $50.92-86.95 \%$ and $8.87-30.21 \%$ of total volatiles and capronaldehyde (4.55-39.90\%), 2(E)-hexenal (25.08-80.99\%) and hexadecane (2.97-11.32\%) were the major constituents, respectively.

The SPME analysis of $V v i$ leaf led to the identification of 6,11 and 4 constituents and the major compounds were capronaldehyde (17.04$37.09 \%), \quad \alpha$-terpinene (7.40-9.60\%), limonene (16.50-47.51\%) and terpinolene (7.45-8.70\%), respectively (Table 4 ). Leaf collected from $2533 \mathrm{~m}$ altitude afforded limonene $(47.51 \%)$ as a major constituent

Table 2: Identified VOCs from the leaf of V. arctostaphylos (Va) growing at different altitudes in Turkey.

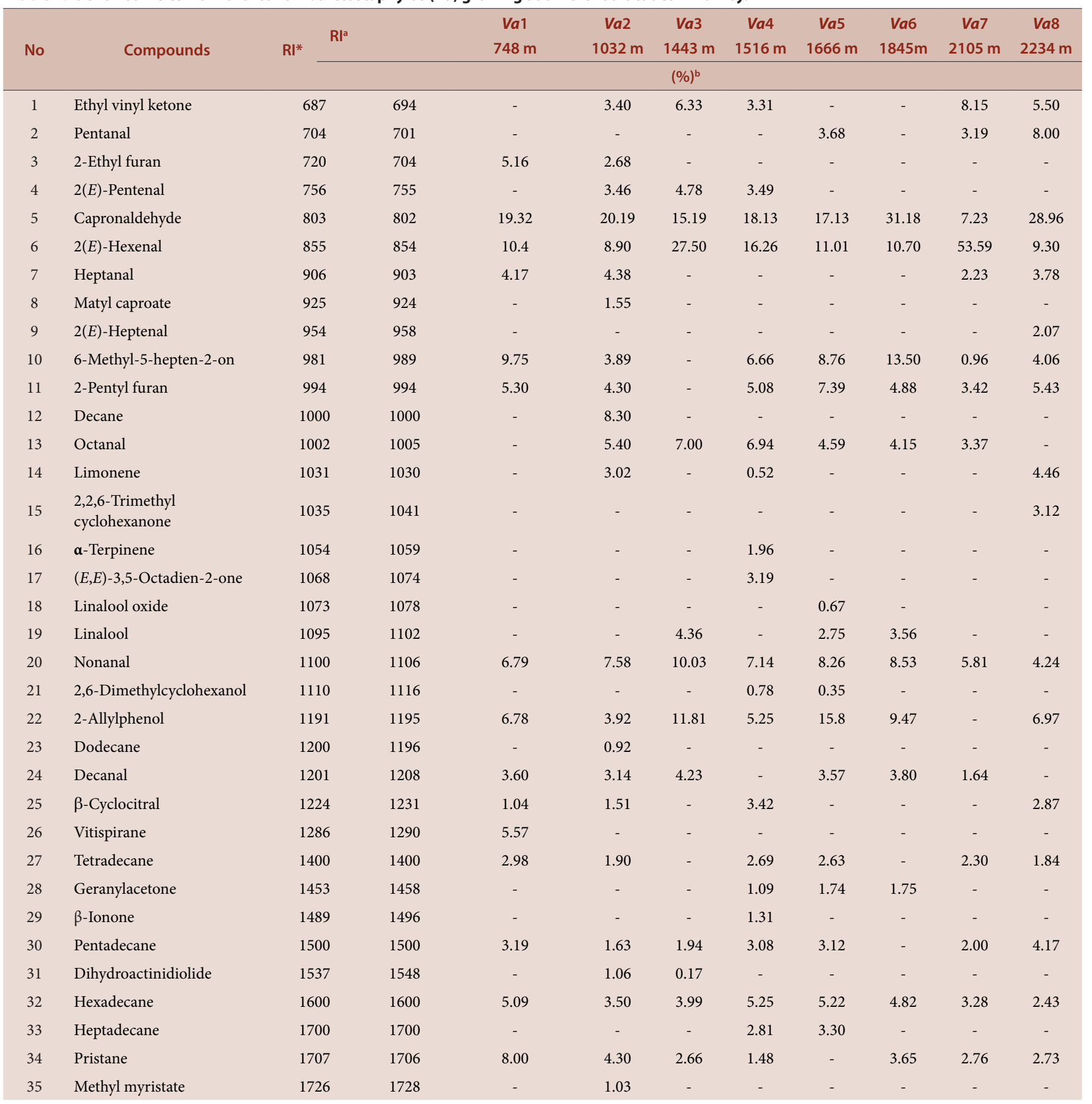




\begin{tabular}{|c|c|c|c|c|c|c|c|c|c|c|}
\hline \multirow[t]{12}{*}{36} & Octadecane & 1800 & 2.85 & - & - & - & - & - & - & - \\
\hline & & Chemical Class; & & & & $\%^{\mathrm{b}}$ and NC & & & & \\
\hline & & Monoterpene: & - & $3.02: 1$ & - & $2.48: 2$ & - & - & - & $7.58: 2$ \\
\hline & & Monoterpenoid: & $1.04: 1$ & $1.51: 1$ & $4.36: 1$ & $3.42: 1$ & $3.42: 2$ & $3.56: 1$ & - & - \\
\hline & & Aldehyde: & 44.61:5 & $53.0: 7$ & 68.73:6 & $51.94: 5$ & $48.24: 6$ & $58.36: 5$ & $77.06: 7$ & $56.25: 6$ \\
\hline & & Alcohol: & - & - & - & $0.78: 1$ & - & - & - & - \\
\hline & & Hydrocarbon: & $22.01: 5$ & $20.55: 6$ & $8.59: 3$ & $16.4: 6$ & $16.01: 5$ & $10.22: 3$ & $10.34: 4$ & $11.17: 4$ \\
\hline & & Aromatics: & $17.14: 3$ & $14.76: 3$ & $11.81: 1$ & $10.33: 2$ & $23.19: 2$ & $14.35: 2$ & $3.42: 1$ & $12.4: 2$ \\
\hline & & Ester: & - & $2.58: 2$ & - & - & - & - & - & - \\
\hline & & Ketone: & $9.65: 1$ & $3.85: 3$ & $6.50: 2$ & $13.16: 3$ & $8.76: 1$ & $13.50: 1$ & $9.11: 2$ & $12.58: 3$ \\
\hline & & Other: & $5.47: 1$ & - & - & $1.31: 1$ & - & - & - & - \\
\hline & & Total: & $99.92: 16$ & $99.32: 23$ & 99.99:13 & $99.82: 21$ & $99.62: 16$ & 99.99:12 & 99.90:14 & $99.90: 17$ \\
\hline
\end{tabular}

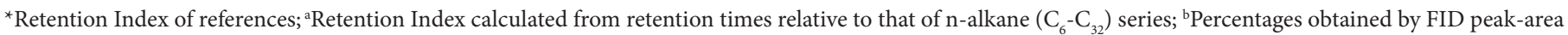
normalization; ${ }^{\circ} \mathrm{NC}$ : number of compounds; V. arctostaphylos species growing at different altitudes in Turkey: Va1: $748 \mathrm{~m}$, Ardeşen-Rize; Va2: $1032 \mathrm{~m}$ Ardeşen-Rize; Va3: 1443 m, Arakl1-Trabzon; Va4: 1516 m, Düzköy-Trabzon; Va5: 1666 m, Doğankent-Giresun; Va6: 1845 m Kürtün-Gümüşhane; Va7: 2105 m, Şavşat-Artvin; Va8: $2234 \mathrm{~m}$, Murgul-Artvin.

Table 3: Identified VOCs and chemical class from the leaf of $\mathrm{V}$. uliginosum(Vu) growing at different altitudes in Turkey.

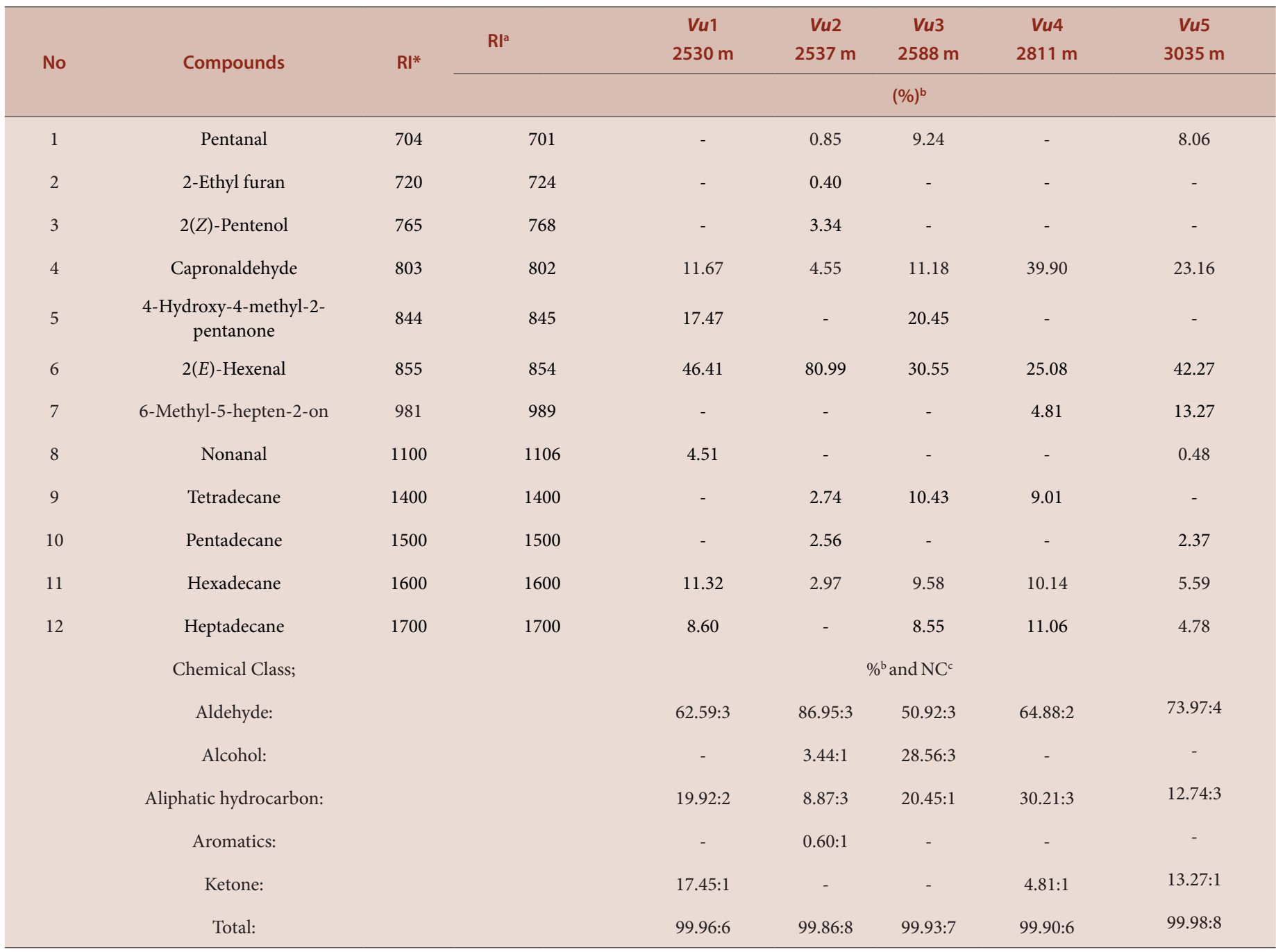

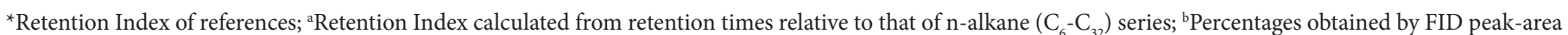
normalization; 'NC: number of compounds; V. uliginosum growing at different altitudes in Turkey: Vu1: 2530 m, Artvin; Vu2: 2537 m, Rize-Anzer; Vu3: 2588 m, Ardahan; Vu4: 2811 m, Trabzon; Vu5: 3035 m, Rize-Ovit. 
Table 4: Identified VOCs and chemical class from leaf of V. vitis-ideae (Vvi) growing at different altitudes in Turkey.

\begin{tabular}{|c|c|c|c|c|c|c|}
\hline \multirow{3}{*}{ No } & \multirow{3}{*}{ Compounds } & \multirow{3}{*}{$\mathrm{RI}^{*}$} & \multirow{3}{*}{$\mathbf{R}^{\mathbf{a}}$} & Vvi1 & Vvi2 & Vvi3 \\
\hline & & & & $2362 \mathrm{~m}$ & $2376 \mathrm{~m}$ & $2533 \mathrm{~m}$ \\
\hline & & & & \multicolumn{3}{|c|}{$(\%)^{b}$} \\
\hline 1 & Ethyl vinyl carbinol & 684 & 689 & 18.13 & - & - \\
\hline 2 & Pentanal & 704 & 701 & 14.60 & 3.90 & - \\
\hline 3 & Acetoin & 711 & 710 & - & 3.05 & - \\
\hline 4 & Capronaldehyde & 803 & 802 & 37.09 & 17.04 & 34.18 \\
\hline 5 & 2(E)-Hexenal & 855 & 854 & 9.64 & - & - \\
\hline 6 & $\boldsymbol{\alpha}$-Terpinene & 1014 & 1021 & - & 7.40 & 9.60 \\
\hline 7 & Limonene & 1031 & 1030 & 16.50 & 30.75 & 47.51 \\
\hline 8 & $\boldsymbol{\gamma}$-Terpinene & 1054 & 1059 & - & 4.60 & - \\
\hline 9 & Terpinolene & 1086 & 1094 & - & 7.45 & 8.70 \\
\hline 10 & Linalool & 1095 & 1102 & - & 6.23 & - \\
\hline 11 & Nonanal & 1100 & 1106 & 4.01 & 1.94 & - \\
\hline 12 & $\boldsymbol{a}$-Terpineol & 1186 & 1192 & - & 14.75 & - \\
\hline \multirow[t]{9}{*}{13} & Pentadecane & 1500 & 1500 & - & 2.90 & - \\
\hline & Chemical Class; & & & \multicolumn{3}{|c|}{$\%^{\mathrm{b}}$ and $\mathrm{NC}^{\mathrm{c}}$} \\
\hline & Monoterpene: & & & $16.50: 1$ & $50.15: 4$ & $65.81: 3$ \\
\hline & Monoterpenoid: & & & - & 20.98:2 & - \\
\hline & Aldehyde: & & & $65.34: 4$ & $22.88: 3$ & $34.18: 1$ \\
\hline & Aliphatic hydrocarbon: & & & - & 2.9:1 & - \\
\hline & Ketone: & & & $18.13: 1$ & - & - \\
\hline & Others: & & & - & $3.05: 1$ & - \\
\hline & Total: & & & $99.97: 6$ & $99.96: 11$ & 99.99:4 \\
\hline
\end{tabular}

${ }^{*}$ Retention Index of references; ${ }^{a}$ Retention Index calculated from retention times relative to that of $\mathrm{n}$-alkane $\left(\mathrm{C}_{6}-\mathrm{C}_{32}\right)$ series; ${ }^{\mathrm{b} P e r c e n t a g e s}$ obtained by FID peak-area normalization; ${ }^{\mathrm{N} C}$ : number of compounds; V. vitis-ideae growing at different altitudes in Turkey: Vvi1: $2362 \mathrm{~m}$ Ardahan-Hanak; Vvi2: $2376 \mathrm{~m}$ Ardahan-Posof; Vvi3: $2533 \mathrm{~m}$ Artvin.

whereas a less percentage of limonene (16.50\%) was found from other altitude $(2362 \mathrm{~m})$. The capronaldehyde was obtained in a high amount form the leaf collected at $2362 \mathrm{~m}$ and $2533 \mathrm{~m}$ altitude. In all three sites, the monoterpene of the $V v i$ leaf collected from the high altitude was higher compared with those collected from the low altitude.

Volatile component analyzes of $\mathrm{Vm}$ leaf collected from different elevations (1917, 2533, 2565, 2613 and $2811 \mathrm{~m}$ ) of the Black Sea region were performed by SPME GC-MS. A total of 5, 7, 12, 6 and 6 compounds were identified, respectively (Table 5 ). The most volatile compounds were illuminated in the sample collected from the $2565 \mathrm{~m}$ altitude. The main volatile constituents of $V m$ at $1917 \mathrm{~m}, 2533 \mathrm{~m}$ and $2565 \mathrm{~m}$ altitudes were capronaldehyde and 2(E)-hexenal. Aldehydes were the main class compounds, except samples harvested at $2613 \mathrm{~m}$ and $2811 \mathrm{~m}$ altitude, monoterpene $(39.4 \%)$ and ketone $(95.27 \%)$ was the major class of compounds, respectively. The ratio of capronaldehyde and 2(E)-hexenal were decreased up to high altitudes.

\section{DISCUSSION}

In this study, the volatile component analysis of Vaccinium species depending on different altitudes, aldehyde compounds were found to be the main component in different proportions. In the literature, the essential oil constituents of the flowering aerial parts of $\mathrm{Va}$ were analyzed by GC-MS and twenty-six compounds, constituting $80.43 \%$ of the oil, were identified. The major compounds were $\alpha$-terpineol (14.99\%) and linalool (13.7\%). ${ }^{8}$ The volatile oil from $V$. bracteatum leaf was analyzed by GC-MS and 49 constituents were reported, which represented about $91.94 \%$ of the total content. The main chemical compounds were terpenes (54.75\%), open chain alkanes (6.93\%), cycloparaffins $(20.1 \%)$, olefins (0.60\%), aromatics (1.60\%), phenol, ether and alcohol (3.39\%), aldehyde and ketone $(2.14 \%)$, ester (1.15\%), heterocyclic compounds $(0.47 \%)$ and amines (0.78\%). Nerolidol (20.01\%), (Z,Z,Z)-1,5,9,9-tetramethyl$1,4,7$-cycloundecatriene (17.99\%) and caryophyllene (9.59\%) were the main components in the identified terpenes. ${ }^{9}$ The GC/MS analyses of the essential oils from dry leaf $V v i$ were predominant to be terpenoids, fatty acids, fatty acid- and carotenoid-derived compounds and $\alpha$-terpineol (4.7\%) and linalool (17.0\%). ${ }^{10}$ The chemical constituents of blueberry seed oil was analyzed by GC-MS and a total of 34 constituents were reported. The contents in the volatiles were menthyl isovalerate (30.06\%), 9,12-octadecadien-1-ol (11.82\%), Z-7-tetradecenal (9.77\%), $\gamma$-sitosterol (6.04\%), $\beta$-sitosterol (4.74\%), phenylethyl alcohol (4.72\%), Z-(13,14-epoxy)tetradec-11-en-1-ol acetate $(4.30 \%)$, retinal $(4.07 \%)$, 1-(+)-ascorbic acid, 6-dihexadecanoate (3.93\%), 9,12-octadecadienoic acid, ethyl ester (3.10\%) and 1,6,10,14,18,22-tetracosahexaen-3-ol $(3.00 \%){ }^{32}$ The chemical compounds of the essential oils obtained from by hydrodistillation from the flowering aerial parts of $\mathrm{Va}$ was assessed by GC/MS analysis. $\alpha$-Pinene (15.5\%), linalool (11.7\%), sandaracopimaradiene $(5.9 \%)$ and safranal $(8.8 \%)$ were mentioned to be major constituents. ${ }^{11}$ The volatile components of $V v i$ juice were analyzed by HS SPME GC-MS and 41 volatile components were detected. The major volatile compound in $V v i$ juice was reported as diisobutyl phthalate, accounting for $17.96 \%$ of total aromatic 


\begin{tabular}{|c|c|c|c|c|c|c|c|c|}
\hline \multirow{3}{*}{ No } & \multirow{3}{*}{ Compounds } & \multirow{3}{*}{$\mathbf{R I}^{*}$} & \multirow{3}{*}{$\mathrm{Rl}^{\mathrm{a}}$} & $V m 1$ & $V m 2$ & $V m 3$ & $V m 4$ & $V m 5$ \\
\hline & & & & $1912 \mathrm{~m}$ & $2533 \mathrm{~m}$ & $2565 \mathrm{~m}$ & $2613 \mathrm{~m}$ & $2811 \mathrm{~m}$ \\
\hline & & & & \multicolumn{5}{|c|}{$\%^{\mathrm{b}}$} \\
\hline 1 & Ethyl vinyl carbinol & 684 & 689 & - & - & - & - & 4.22 \\
\hline 2 & 3-Penten-2-one & 733 & 739 & 9.44 & - & 14.52 & 93.60 & - \\
\hline 3 & Capronaldehyde & 803 & 802 & 20.26 & 11.50 & 37.26 & 1.01 & 14.66 \\
\hline 4 & 4-Hydroxy-4-methyl-2-pentanone & 844 & 845 & 19.94 & - & - & 1.67 & - \\
\hline 5 & 2(E)-Hexenal & 855 & 854 & 37.59 & 15.00 & 18.18 & 1.31 & 34.13 \\
\hline 6 & a-Pinene & 932 & 938 & - & 12.55 & - & - & \\
\hline 7 & 1-Octen-3-ol & 976 & 979 & - & - & - & - & 2.70 \\
\hline 8 & 6-Methyl-5-hepten-2-on & 981 & 989 & 3.86 & - & 13.82 & - & 9.36 \\
\hline 9 & 2-Pentyl furan & 994 & 994 & - & - & - & - & 1.65 \\
\hline 10 & p-Cymene & 1020 & 1029 & - & 7.12 & - & - & - \\
\hline 11 & Limonene & 1031 & 1030 & - & 19.99 & - & - & - \\
\hline 12 & 2,2,6-trimethyl Cyclohexanone & 1035 & 1041 & - & - & - & - & 4.94 \\
\hline 13 & Nonanal & 1100 & 1106 & 8.88 & - & 2.87 & - & 2.58 \\
\hline 14 & 2-Bornanone & 1161 & 1154 & - & 32.86 & - & - & - \\
\hline 15 & $\beta$-Cyclocitral & 1224 & 1231 & - & - & - & 0.71 & 2.76 \\
\hline 16 & Vitispirane & 1286 & 1290 & - & - & - & 1.30 & - \\
\hline 17 & Tridecane & 1300 & 1299 & - & - & - & - & 6.60 \\
\hline 18 & Tetradecane & 1400 & 1400 & - & - & - & - & 8.03 \\
\hline 19 & Hexadecane & 1600 & 1600 & - & - & 8.70 & - & 4.57 \\
\hline \multirow[t]{10}{*}{20} & Heptadecane & 1700 & 1700 & - & - & 4.61 & - & 3.75 \\
\hline & Chemical Class; & & & \multicolumn{5}{|c|}{$\%^{\mathrm{b}}$ and $\mathrm{NC}^{\mathrm{c}}$} \\
\hline & Monoterpene: & & & - & 39.4:3 & - & - & - \\
\hline & Monoterpenoid: & & & - & $32.9: 1$ & - & $0.71: 1$ & $2.76: 1$ \\
\hline & Aldehyde: & & & $66.73: 3$ & $27.6: 2$ & $58.31: 3$ & $2.32: 2$ & $51.37: 3$ \\
\hline & Alcohol & & & - & - & - & - & $2.70: 1$ \\
\hline & Aliphatic hydrocarbon: & & & - & - & $13.31: 2$ & - & 22.95:4 \\
\hline & Ketone: & & & $33.24: 3$ & - & $28.34: 2$ & $95.27: 2$ & $18.52: 3$ \\
\hline & Others: & & & - & - & $3.05: 1$ & $1.3: 1$ & - \\
\hline & Total: & & & $99.97: 6$ & 99.99:6 & $99.96: 7$ & $99.96: 6$ & $99.95: 12$ \\
\hline
\end{tabular}

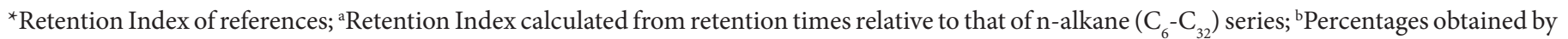
FID peak-area normalization; 'NC: number of compounds; V. myrtillus species growing at different altitudes in Turkey: Vm1: 1917m, GümüşhaneKürtün,; Vm2: 2533m, Artvin-Şavşat,; Vm3: 2565m, Rize-Ardeșen,; Vm4: 2613m, Ardahan-Hanak,; Vm5: 2811m,Trabzon-Çaykara.

compounds. ${ }^{12}$ The volatile components from the fresh leaf buds of $V$. dunalianum var. dunalianum were mentioned. 27 Compounds has been identified and decahydro dimethylnaphthalene (47.04\%), linalool (3.19\%), 3,7-dimethyl-1,5,7-octatrien-3-ol (1.40\%) and benzene acetaldehyde $(1.03 \%)$ were the main compounds. ${ }^{13}$ The floral volatile compounds of $V$. angustifolium, $V$. varingiaefolium, $V$. arboreum and $V$. poasanum has been provided. A total of 40 from $V$. angustifolium, 34 for V. varingiaefolium, 37 for $V$. arboreum and 17 for $V$. poasanum volatile compounds were detected in the headspace surrounding flowers. The most abundant volatile compounds for the each species was reported to be $\alpha$-pinene for $V$. angustifolium (23\%) and V. arboreum (63\%), methyl benzoate for $V$. varingiaefolium (18\%) and ethyl benzene for $V$. poasanum $(21 \%){ }^{14}$ Five volatile compounds consisting of butyl butanoate, cis3-hexen-1-ol, $\alpha$-terpineol, geraniol and 2(E)-hexenal has been found from $V$. corymbosum using GC-MS. ${ }^{15} \mathrm{Vm}$ juice has been analyzed by HS SPME GC-MS and altogether, 56 volatile compounds were identified. ${ }^{16}$
The complexity of $V m$ aroma has been explored by SPME GC-MS. This comprehensive characterization of aroma allowed the identification of volatile organic compounds, for the most aldehydes, alcohols, terpenoids, and esters. ${ }^{17} \mathrm{~A}$ study has been conducted to determine the antifungal and the phytotoxic activity of $\mathrm{Vm}$ plant essential oil. ${ }^{18}$ In another work, volatile compounds and the antifungal activity of Bilberry essential oil of $V m$ were mentioned and 22 components were identified as mainly 1,8 -cineole (41.07\%), $\beta$-linalool (12.72\%), $\alpha$-pinene $(12.17 \%)$ and myrtenol (6.48\%). ${ }^{19}$ Polar metabolites of leaf of $V m$ and $V v i$ has been studied by HPLC-DAD, HPLC-MS and GC-FID. Chlorogenic acid was the major phenolic compounds in bilberry leaf and arbutin in lingonberry leaf. Flavonol glycosides were another major group of phenolic in bilberry [5-28 mg/g DM (dry mass)] and lingonberry (15$20 \mathrm{mg} / \mathrm{g} \mathrm{DM}$ ) leaf. ${ }^{20}$ The extracts of entire fruits and leaf of $\mathrm{Vm}$ collected in Finland and Poland has been quantitated by GC-FID/MS and the 
main bilberry constituents were found to be $\alpha$-and $\beta$-amyrin, $\alpha$-and $\beta$-amyrenone, campesterol, cholesterol and citrostadienol. ${ }^{21}$

\section{CONCLUSION}

Vaccinium species is one of the industrial medicinal plant that is traditionally used for the treatment of diabetes throughout the world. VOCs composition of the $V a, V u, V v i$ and $V m$ leaf has been analyzed. Comparisons based on the mean relative amount of the volatile components in different sites showed significant differences among populations at different altitudes. In all three and five sites, the monoterpene and aldehydes ratio of the $V v i, V m$ and $V u$ collected from the low altitude was higher compared with those collected from the high altitude, respectively. The aldehydes ratio of the $\mathrm{Va}$ harvested from the all eight altitudes was more or less the same. Principal components analyzed based on the mean relative amounts of the volatile components have led to the identification of three chemotypes (capronaldehyde, 2(E)-hexenal and nonanal). Since, the amount of plant constituents affected by altitude and time collected would vary accordingly. These results suggest that altitude is a factor influencing the volatile components of these plants.

\section{ACKNOWLEDGEMENT}

This research was supported by KTÜ-BAP (TYL-2017-6714) and the authors are thankful to the Faculty of Pharmacy research facilities, Karadeniz Technical University, Turkey.

\section{CONFLICT OF INTEREST}

The authors declare no conflict of interest.

\section{ABBREVIATIONS}

Va: V. arctostaphlyos; Vu: V. uliginosum; Vvi: V. vitis-idaea; Vm: V. myrtillus; SPME: Solid phase micro extraction; GC-MS: Gas Chromatography-Mass Spectrometry; HS: Headspace; VOC: Volatile organic compound; HPLC: High-Performance Liquid Cromatography; DVB: Diviniylbenzene; PDMS: Polydimethylsiloxane; FID: Flame ionization detector; mL: Millilitre; KTUB: Karadeniz Technical University, Herbarium of Biology (Turkey); C\&Y: Coşkunçelebi and Yilmaz; RI: Retention Index; NC: Number of compounds.

\section{REFERENCES}

1. Cronquist A. An integrated system of classification of flowering plants. New York: Columbia University Press. 1981;1262.

2. Stevens PFA. Classification of the Ericaceae: Subfamilies and tribes. Bot J Linn Soc. 1971;64(1):1-53.

3. Vander KSP. The genus Vaccinium in North America. Research Branch Publish Agriculture: Canada, Ottawa. 1988.

4. Martineau LC, Couture A, Spoorab D, Benhaddou-Andaloussi A, Harris C, Meddahab B, et al. Anti-diabetic properties of the Canadian lowbush blueberry Vaccinium angustifolium Ait. Phytomedicine. 2006;13(10):612-23.

5. Bljaji'c K, Petlevski R, Vuji'c L, 'Cǎci'c A, Šoštari'c N, Jablan J, et al. Chemical composition, antioxidant and $\alpha$-glucosidase-inhibiting activities of the aqueous and hydroethanolic extracts of Vaccinium myrtillus leaves. Molecules. 2017;22(5):703.

6. Ayaz FA, Hayırlıoğlu-Ayaz S, Gruz J, Novak O, Strnad M. Separation, characterization and quantitation of phenolic acids in a little-known blueberry (Vaccinium arctostaphylos L.) fruit by HPLC-MS. J Agric Food Chem. 2005;53(21):8116-22.
7. Rimando AM, Kalt W, Magee JB, Dewey J, Ballington JR. Resveratrol, pterostilbene and piceatannol in Vaccinium berries. J Agric Food Chem. 2004;52(15):4713-9.

8. Nickavar B, Salehi-Sormagi M, Amin G, Daneshtalab M. Steam volatiles of Vaccinium arctostaphylos. Pharm Biol. 2002;40(6):448-9.

9. Yang X, Xiao S, Xu Y, Han Z, Wu Y. Analysis of volatile oil from Vaccinium bracteatum Thumb. leaves by gas chromatography-mass spectrometry. Biomass Chem Eng. 2008;42(2):23-6.

10. Radulovic N, Blagojevic P, Palic R. Comparative study of the leaf volatiles of Arctostaphylos uva-ursi (L.) Spreng. and Vaccinium vitis-idaea L. (Ericaceae). Molecules. 2010;15(9):6168-85.

11. Teimouri M. The chemical composition and antimicrobial activity of essential oils of Vaccinium arctostaphylos L. Int J Adv Biol Biomed Res. 2014;2(11):283741.

12. Yang $H$, Liu Y, Guo D. Volatile components analysis of Vaccinium vitis-idaea juice and its fermented wine by GC-MS. Zhongguo Niangzao. 2014;33(12):133-8.

13. Yin J, Jiang L, Jiang Y, Wang J, Zhao P. GC-MS analysis of volatile components from fresh leaf-buds of Vaccinium dunalianum var. dunalianum. J Southwest Forestry Univer. 2013;33(2):100-3.

14. Forney CF, Javorek SK, Jordan MA, Vander KSP. Floral volatile composition of four species of Vaccinium. Botany. 2012;90(5):365-71.

15. Liburd OE. Identification of host volatile compounds for monitoring blueberry maggot fly. Int J Fruit Sci. 2004;3(3/4):307-12.

16. Liu S, Laaksonen O, Yang B. Volatile composition of bilberry wines fermented with non-Saccharomyces and Saccharomyces yeasts in pure, sequential and simultaneous inoculations. Food Microbiol. 2019;80:25-39.

17. Farneti B, Grisenti M, Ajelli M, Giongo L, Khomenko I, Betta E, et al. Exploring blueberry aroma complexity by chromatographic and direct-injection spectrometric techniques. Front Plant Sci. 2017;8:617.

18. Yilar M. Phytotoxic and antifungal activities of thyme, bilberry, sage essential oils. Fresenius Environ Bull. 2018;27(8):5559-69.

19. Bayar Y, Onaran A, Yilar M, Gul F. Determination of the essential oil composition and the antifungal activities of bilberry (Vaccinium myrtillus L.) and bay laurel (Laurus nobilis L.). J Essent Oil Bear PI. 2018;21(2):548-55.

20. Liu P, Lindstedt A, Markkinen N, Sinkkonen J, Suomela J, Yang B. Characterization of metabolite profiles of leaves of bilberry (Vaccinium myrtillus L.) and lingonberry (Vaccinium vitis-idaea L.). J Agric Food Chem. 2014;62(49):12015 26.

21. Szakiel A, Paczkowski C, Huttunen S. Triterpenoid content of berries and leaves of bilberry Vaccinium myrtillus from Finland and Poland. J Agric Food Chem. 2012;60(48):11839-49

22. Renda G, Tosun G, Yaylı N. SPME GC/MS analysis of three Ornithogalum L. species from Turkey. Rec Nat Prod. 2016;10(4):497-502.

23. Korkmaz FM, Özel MB, Tüzüner T, Korkmaz B, Yaylı N. Antimicrobial activity and volatile constituent analysis of three commercial herbal toothpastes containing Aloe vera L. and Fragaria vesca L. extracts. Niger J Clin Pract. 2019;22(5):718726.

24. Renda G, Çelik G, Korkmaz B, Alpay Ş, Yaylı N. Antimicrobial activity and analyses of six Geranium L. species with headspace SPME and hydrodistillation. J Essent Oil Bear PI. 2016;19(8):2003-16.

25. Shelke V, Bhot M. GC-MS Analysis of bio-active compounds in ethanolic extract of leaf and stem of Asclepias curassavica L. Int J Pharm Investig. 2019;9(2):6770 .

26. Adams RP. Identification of essential oil components by gas chromatography/ mass spectrometry. Allured Publishing Corporation Carol Stream I. 2007.

27. Adams RP, Morris JA, Pandey RN, Schwarzbach AE. Cryptic speciation between Juniperus deltoides and Juniperus oxycedrus (Cupressaceae) in the mediterranean. Biochem Syst Ecol. 2005;33(8):771-87.

28. Yue T, Chi M, Song $C$, Liu M, Jiang-Fei Y, Zhang Z, et al. Aroma characterization of cabernet sauvignon wine from the plateau of yunnan (China) with different altitudes using SPME-GC/MS. Int J Food Prop. 2015;18(7):1584-96.

29. Bylaite $E$, Meyer AS. Characterisation of volatile aroma compounds of orange juices by three dynamic and static headspace gas chromatography techniques. Eur Food Res Technol. 2006;222(1-2):176-84

30. Nickavar B, Salehi-Sormagi MH, Amin G, Daneshtalab M. Steam volatiles of Vaccinium arctostaphylos. Pharm Biol. 2002;40(6):44849.

31. Quijano CE, Salamanca G, Pino JA. Aroma volatile constituents of Colombian varieties of mango (Mangifera indica L.). Flavour Frag J. 2007;22(5):401-16.

32. Qu X, Bai Y, LiY, Yang Y, Jia Q, Nie F. Analysis on volatiles from blueberry seed oil by GC-MS. Guizhou Nongye Kexue. 2013;41(10):6466.

Article History: Submission Date : 25-08-2020; Revised Date : 15-09-2020; Acceptance Date : 20-10-2020.

Cite this article: Erik İ, Kılıç G, Yaylı SS, Yılmaz G, Coşkunçelebi K, Yaylı N. Altitude Variation in Volatile Composition of Blueberry Leaf Analyzed by SPME GC-MS Int. J. Pharm. Investigation, 2020;10(4):519-25. 